УДК 81-26

10.00.00 Филологические науки

СПЕЦИФИКА ПЕРЕВОДА

ЗВУКОПОДРАЖАНИЙ В ЖАНРЕ

ЛИТЕРАТУРНОЙ СКАЗКИ

(НА МАТЕРИАЛЕ СКАЗОК К.С. ЛЬЮИСА «ХРОНИКИ НАРНИИ»)

Николаева Елена Сергеевна

AuthorID: 842492

кандидат филологических наук, доцент кафедры лингвистики и межкультурой коммуникации lenikol@yandex.ru

Агабабян Сусанна Рубеновна

AuthorID: 254520

кандидат психологических наук, доцент кафедры лингвистики и межкультурой коммуникации

г.Ростов-на-Дону, Россия

asusanna@mail.ru

Статья посвящена рассмотрению особенностей трансляции звукоподражаний при переводе литературной сказки на материале сказок К.С.

Льюиса «Хроники Нарнии». В работе проводится сопоставительный анализ английской литературной сказки и ее перевода на русский язык для выявления закономерностей трансляции звукоподражаний в художественном тексте.

В статье указывается, что в детской художественной литературе звукоподражанию отводится особая роль при создании косвенной характеристики персонажа, описании его эмоционального состояния, определенной атмосферы. В сказках К.С. Льюиса «Хроники Нарнии» широко представлены ономатопы четырех лексических групп: подражания звуковым проявлениям человека; подражания звуковым проявлениям животных, птиц; подражания звуковым проявлениям природных явлений; подражания звуковым проявлениям неодушевленных предметов. Трансляция звукоподражаний в текст сказок может представлять собой определенную переводческую проблему. В статье обосновывается специфика подбора эквивалентов англоязычной звукоподражательной лексике в русском языке. Подчеркивается особая значимость передачи авторских ономатопов, которые могут быть переданы либо транскрипцией, либо вариантным соответствием. Делается вывод о том, что в большинстве случаев переводчик стремится подобрать стандартный ономатоп в качестве переводческого эквивалента, который будет естественно входить в ткань повествования
UDC $81-26$

Philology

\section{SPECIFICATION OF SOUND TRANSMISSION IN THE LITERATURE FAIRY TALE (ON THE MATERIAL OF KS LEWIS'S FAIRY TALE "CHRONICLES OF NARNIYA")}

\author{
Nikolaeva Elena Sergeevna \\ AuthorID: 842492 \\ Candidate of Philology, Associate Professor of the \\ Department of Linguistics and Intercultural \\ Communication \\ lenikol@yandex.ru
}

Agababyan Susanna Rubenovna

AuthorID: 254520

Candidate of Psychological Sciences, Associate

Professor of the Department of Linguistics and

Intercultural Communication

Rostov-on-Don, Russia

asusanna@mail.ru

The article is devoted to the analysis of the features of the translation of onomatopoeic sounds when translating a literary tale on the material of the fairy tales of K.S. Lewis "The Chronicles of Narnia." The work compares the English literary fairy tale and its translation into Russian in order to reveal the laws of the translation of onomatopoeias in the literary text. The article points out that in children's literature a special role is assigned to onomatopoeia when creating an indirect characterization of the character, describing its emotional state, a certain atmosphere. Four lexical groups of onomatopoeias are thought to be widely represented in the fairy tales "The Chronicles of Narnia" written by K.S. Lewis: imitations of sounds produced by human beings; imitations of sounds produced by animals and birds sounds; imitations of sounds of natural phenomena; imitations of sounds of inanimate objects. Translation of onomatopoeias into the text of fairy tales can represent a certain problem for translators. The article substantiates the specificity of the equivalents selection of the English-speaking onomatopoeic vocabulary in Russian language. It emphasizes the special significance of the transfer of author's onomatops, which can be translated either by transcription or by variant correspondence. The conclusion is drawn that in most cases the translator seeks to select a standard onomatop as a translation equivalent, which will naturally enter the narrative fabric 
КЛючевЫе слова: ОНОМАТОПЕЯ, ПЕРЕВОД, ЛИТЕРАТУРНАЯ СКАЗКА, ПЕРЕВОДЧЕСКИЕ ТРАНСФОРМАЦИИ
Keywords: ONOMATOPOEIA, TRANSLATION, LITERARY FAIRY TALE, TRANSLATION TECHNIQUES

Doi: 10.21515/1990-4665-132-111

\section{Специфика перевода звукоподражаний в жанре литературной сказки (на материале сказок К.С. Льюиса «Хроники Нарнии»)}

Целью настоящей статьи является сопоставительный анализ английской литературной сказки и еe перевода на русский язык для выявления закономерностей трансляции звукоподражаний в художественном тексте.

Звукоподражание, или ономатопея - это особый разряд слов, которые «не содержат эмоций или волеизъявлений, представляя собой приблизительное, условное воспроизведение языковыми средствами явлений действительности» [9, с. 28]. Несмотря на универсальный характер звукоизобразительности, состав звукоподражаний будет отличаться в разных языках. По справедливому замечанию Т.Ю. Ефимовой, основной причиной подобных различий является то, что «сами звуки-источники имеют сложную природу, и, поскольку точная имитация их средствами языка невозможна, каждый язык выбирает одну из составных частей этого звука как образец для подражания» [6].

Детская литературная сказка в качестве объекта исследования была выбрана неслучайно, так как именно в этом жанре наиболее плодотворно раскрывается потенциал звукоподражательных единиц. Как известно, одной из особенностей литературной сказки является приближенность к детской речи. Язык детской литературной сказки должен помочь ребенку расширить горизонты, научить новым формам речи [1, с. 156], но вместе с тем, язык сказки должен быть понятен. В качестве одного из средств создания художественного пространства детской литературной сказки выступает звукоподражательная лексика. Звукоподражания придают яркость звуковой организации текста сказки и обладают своей интонацией. 
В научной литературе традиционной является классификация звукоподражаний по источнику происхождения того или иного звука, ставшего основой для звукоподражательного слова. Исходя из происхождения звукоподражаний, предлагается их деление на следующие группы: подражание звуковым проявлениям человека; подражание голосам животных и птиц; подражания звуковым явлениям природы, звукам, производимым неодушевленными предметами [4]. В зависимости от употребительности звукоподражаний в литературе, их можно разделить на: общепринятые, составляющие основной фонд звукоподражательного словаря, и окказиональные (авторские) ономатопы [3].

Звукоподражания широко используются в детской художественной литературе для косвенной характеристики персонажа, его эмоционального состояния, для создания определенной атмосферы и могут стать серьезной проблемой при переводе на другой язык. Звукоподражания служат писателю «не только для образного представления действительности, но и для выражения своего отношения к типам, персонажам, человеческим поступкам» $[10$, с. 145$]$.

Для анализа особенностей перевода английских звукоподражательных единиц на русский язык в настоящей статье рассматриваются произведения Клайва Стейплза Льюиса из цикла «Хроники Нарнии» и их переводы на русский язык, выполненные Г.А. Островской [8]. Методом сплошной выборки было выделено и проанализировано 112 случаев употребления английских звукоподражаний, которые можно поделить на следующие группы: 


\begin{tabular}{|c|c|c|}
\hline & Английский (оригинал) & Перевод на русский язык \\
\hline $\begin{array}{l}\text { Подражания } \quad \text { звуковым } \\
\text { проявлениям человека }\end{array}$ & $\begin{array}{l}\text { a-shoo! } \\
\text { cough-cough } \\
\text { Coo-ee! } \\
\text { faugh } \\
\text { ho-ho } \\
\text { pad-pad-pad } \\
\text { phew, pah } \\
\text { shoo } \\
\text { sh } \\
\text { thump-thump } \\
\text { whew }\end{array}$ & $\begin{array}{l}\text { апчхи! } \\
\text { кхе-кхе } \\
\text { Ау! } \\
\text { тьфу } \\
\text { хо-хо } \\
\text { шлеп-шлеп } \\
\text { фу, тьфу } \\
\text { шу } \\
\text { ш-ш } \\
\text { топ-топ } \\
\text { ух, ого, фух, у-у }\end{array}$ \\
\hline $\begin{array}{l}\text { Подражания } \\
\text { проявлениям } \\
\text { птиц и насекомых }\end{array}$ & $\begin{array}{l}\text { bree-hee-hee! } \\
\text { buzz } \\
\text { Caw } \\
\text { clop-clop, cloppety-clop } \\
\text { haw-hee-haw-hee-hee } \\
\text { puss, puss } \\
\text { poo-tee-weet } \\
\text { tuwhoo! Tu-whoo! }\end{array}$ & $\begin{array}{l}\text { иго-го! } \\
\text { ж-ж-ж } \\
\text { кар-р-р } \\
\text { цок-цок } \\
\text { иа-иа-иа } \\
\text { кис-кис-кис, } \\
\text { пьюти-фьют } \\
\text { ту-ух! ту-ух! }\end{array}$ \\
\hline $\begin{array}{lr}\text { Подражания } & \text { звуковым } \\
\text { проявлениям } & \text { природных } \\
\text { явлений } & \end{array}$ & $\begin{array}{l}\text { drip-drip-drip } \\
\text { drop-drop } \\
\text { boom-boom-boom } \\
\text { boom } \\
\text { rat-tararat }\end{array}$ & $\begin{array}{l}\text { кап-кап-кап } \\
\text { кап-кап } \\
\text { бум-бум-баба-бум, } \\
\text { бум, бум румбум } \\
\text { бум } \\
\text { трах-тарарах }\end{array}$ \\
\hline $\begin{array}{l}\text { Подражания } \quad \text { звуковым } \\
\text { проявлениям } \\
\text { неодушевленных предметов }\end{array}$ & $\begin{array}{l}\text { bang } \\
\text { beep-beep } \\
\text { bong! } \\
\text { bump } \\
\text { clink } \\
\text { crash } \\
\text { Da dad a dum! } \\
\text { dong-dong } \\
\text { dum-dum } \\
\text { pip-pip } \\
\text { snip-snip-snip } \\
\text { snap } \\
\text { splash, } \\
\text { thump, } \\
\text { tic-tac } \\
\text { tick-tock-tick-tock } \\
\text { thrum-thrum-thrum }\end{array}$ & $\begin{array}{l}\text { бац, бряк } \\
\text { бип-пип } \\
\text { дон! } \\
\text { бах } \\
\text { дзинь } \\
\text { трах-та-ра-рах! шлеп! } \\
\text { Та та та тум! } \\
\text { дин-дин, динь-бом } \\
\text { та-та-та, тра-та-та } \\
\text { би-бип } \\
\text { чик-чик-чик } \\
\text { хлоп, крах } \\
\text { плюх } \\
\text { бах, стук } \\
\text { тик-так } \\
\text { тик-так-тик-так } \\
\text { тра-ра-ра, тру-ру-ру }\end{array}$ \\
\hline
\end{tabular}

было установлено, что большинство звукоподражаний английского языка может быть переведено при помощи русских эквивалентов. Рассмотрим несколько примеров: «Ho-ho-ho!» he chuckled. «I thought you were all so 
eager to see Tashlan face to face!» [11]. - Хо-хо-хо, - хихикал он, - я думаю, вы будете в восторге, взглянув на Ташлана лищом к лииу! [8]. «Puss, puss,» said Shasta. «I suppose you're not a talking cat.»[11]. - Кис-кис-кис, неуверенно сказал Шаста. - Ты говорить не умеешь? [8].

В анализируемых сказках наблюдается устойчивая тенденция перевода первообразных ономатопов при помощи звукоподражательных глаголов: «Whew!»whistled Digory.[11]. Дигори присвистнул. [8]. «What had she done?» «Ah, poor woman,» said Uncle Andrew. [11]. 3a чmo? Бедняжка! - вздохнул дядя [8].

На русский язык звукоподражания «whew» и «ah» переданы звукоподражательными глаголами «присвистнуть» и «вздохнуть»:

Перевод звукоподражаний в текстах сказок также осуществлялся с помощью незвукоизобразительной лексики, когда имитация звучания как таковая оказывалась не столь важной для данного контекста: «Phew!» gasped Eustace. "It's like something dead [11]. Ну и ну, - сдерживая дыхание, произнес Юстэс, - как будто что-то мертвое. [8].

В ряде случаев нами был зафиксировано применение описательного метода перевода при трансляции английских звукоподражаний: The Queen gave a long drawn «A-a-ah!» And Digory saw on her face that same hungry and greedy look which he had lately seen on Uncle Andrew's [11]. И mym королева испустила не то вздох, не то рев, и лицо ее исказилось той же жадностью, какую он недавно видел на физиономии дядюшки Эндрью [8].

В данном примере Г.А. Островская посчитала невозможным выразить в переводе все оттенки значения звукоподражательной единицы одной лексемой.

В некоторых случаях в нашем материале исследования наблюдается перевод английского звукоподражания либо при помощи незвукоизобразительной лексики, либо звукоподражание опускается в тексте перевода: Suddenly he heard a horn - not a great throbbing horn like 
the horns of Tashbaan but a merry call, Ti-ro-to-to-ho! [11]. Вдруг он усльшал звук охотничьего рога - не грозный, как в Ташбаане, а радостный и весельий [8].

С другой стороны отмечается и обратная ситуация, когда переводчик использует звукоподражание там, где его нет в оригинале для более точной характеристики персонажа: Show us how to help, show us how, how. Howhow-how? [11]. Скажите нам, как помочь. Где нужна помощь? Где, гав, гдe?» [8].

Перевод окказиональных звукоподражаний представляет определенные трудности, так как подобные единицы являются индивидуальными проявлениями авторского стиля. По меткому выражению С. Влахова и С. Флорина, они «явно “торчат над строкой”, так как рассчитаны на определенный стилистический эффект» [2, с. 245]:

If it were even a horse - «e'en -a hor - eeh - auh, eeh-auh.» [11]. Xomb в коня... в коня-а-э-а-ио-о-о! [8]. «Aii - Aii - Aaow - Awah,» screamed the Cat [11]. Ay-ay-y, - завыл кот [8].

В приведенных примерах использован прием транскрибирования окказиональных звукоподражаний. Перевод авторских ономатопей при помощи традиционных функциональных аналогов в тексте сказки актуализирован в случаях воспроизведения незнакомых читателю перевода звуков, неадекватных по значению или трудно произносимых на языке перевода: And all the time the squeak of the leather, the jingle of the bits, and the noise of the hoofs-not Propputty-propputty as it would be on a hard road, but Thubbudy-thubbudy on the dry sand [11]. Копьта звучали глухо - не «цок-цок-цок», а вроде бы «хох-хох-хох» [8].

Слова «propputty», «thubbudy» и «tiddely pom» отсутствуют в русскоанглийском словаре междометий и релятивов [7]. Данный факт заставляет переводчика искать аналог в русском языке, который подходил бы по смыслу в данной ситуации и мог бы означать стук копыт и веселую песню. 
В следующем примере при переводе авторского звукоподражания wha-ha-ha-ha-ha Г.А. Островская использует функциональный аналог гого-го, который обозначает «звукоподражание раскатистому хохоту» [7, с. 427]: «Actually it came out in a sort of neigh - «Ridden the wha-ha-ha-haha...» [11]. Во всяком случае, хотел усмехнуться, а вышло скорей «го-гого!..»... [8].

Подводя итог проведенному исследованию, можно сделать следующие выводы:

1. Большинство звукоподражаний английского языка может быть переведено при помощи звукоподражаний ПЯ. Своеобразие английских ономатопоэтических слов проявляется в том, что один ономатоп в английском языке может иметь несколько значений. Соответственно, для передачи каждого значения требуется отдельный эквивалент в русском языке.

2. Авторские ономатопы могут быть переданы либо транскрипцией, либо вариантным соответствием. Однако в большинстве случаев переводчик стремится подобрать стандартный ономатоп в качестве переводческого эквивалента, который будет естественно входить в ткань повествования.

3. В целом, русскому переводчику при передаче английских звукоподражаний из произведений Клайва Стейплза Льюиса «Хроники Нарнии» удалось подобрать корректные аналоги в ПЯ.

\section{Список литературы}

1. Арзамасцева И.Н., Николаева С.А. Детская литература. - 3 изд. перераб. и доп. - М. Издательский центр «Академия», 2005 - 576с.

2. Влахов С., Флорин С. Непереводимое в переводе. - М.: Международные отношения, 1980. $-343 \mathrm{c}$.

3. Германович А.И. Междометия и звукоподражательные слова русского языка: автореф. дис. ... д. филол. наук. - Симферополь, 1961. - 59 с. $458 \mathrm{c}$.

4. Дудников А.В. Современный русский язык. - М.: Высшая школа, 1990. - 
5. Ермакова Н.М. Ономатопея: англо-русские параллели в переводе: автореф. дисс. ... канд. филол. наук. - Спб, 1993. - 17с.

6. Ефимова Т.Ю. Кис-кис! Мяу! Или кое-что о звукоподражаниях // Вестник Олимпиады «Светозар». - 2004. - №9. - [Электронный ресурс]. - Режим доступа: URL: http://svetozar.org/lingvo/phonetics/7.shtml (дата обращения 21.04.2017).

7. Квеселевич Д.И., Сасина В.П. Русско-английский словарь междометий. М.: ООО Апрель, ООО АСТ, 2001. - 512с.

8. Льюис К.С. Хроники Нарнии. - Пер. с англ. Г. Островской. - М.: Эксмо, 2010. - 992c. - [Электронный Ресурс]. - Режим доступа: URL: //http://www.ereading.club/book.php?book $=75189$

9. Николаева Е.С. Междометия в прагмалингвистическом аспекте (на материале русского и английского языков): дис. ... канд. филол. наук: 10.02.19 Ростов н/Д, 2006. - $180 \mathrm{c.}$

10. Фатюхин В.В. Особенности перевода звукоподражаний и междометных глаголов (на материале русского и английского языков): дис. ... канд. филол. наук: 10.02.20 Москва, 2000. 184c.

11. Lewis C.S. The Chronicles of Narnia. - Harper Collins Children's Books, 2011. $-224 \mathrm{c}$.

\section{References}

1.Arzamasceva I.N., Nikolaeva S.A. Detskaya literatura. - 3 izd. pererab. i dop. - M. Izdatel'skij centr «Akademiya», 2005 - 576s.

2.Vlahov S., Florin S. Neperevodimoe v perevode. - M.: Mezhdunarodnye otnosheniya, 1980. $-343 \mathrm{~s}$.

3.Germanovich A.I. Mezhdometiya i zvukopodrazhatel'nye slova russkogo yazyka: avtoref. dis. ... d. filol. nauk. - Simferopol', 1961. - 59 s.

4.Dudnikov A.V. Sovremennyj russkij yazyk. - M.: Vysshaya shkola, 1990. - 458s.

5.Ermakova N.M. Onomatopeya: anglo-russkie paralleli v perevode: avtoref. diss. ... kand. filol. nauk. - Spb, 1993. - 17s.

6.Efimova T.YU. Kis-kis! Myau! Ili koe-chto o zvukopodrazhaniyah // Vestnik Olimpiady «Svetozar». - 2004. - №9. - [EHlektronnyj resurs]. - Rezhim dostupa: URL: http://svetozar.org/lingvo/phonetics/7.shtml (data obrashcheniya 21.04.2017).

7.Kveselevich D.I., Sasina V.P. Russko-anglijskij slovar' mezhdometij. - M.: OOO Aprel', OOO AST, 2001. - 512s.

8.L'yuis K.S. Hroniki Narnii. - Per. s angl. G. Ostrovskoj. - M.: EHksmo, 2010. - 992s. - [EHlektronnyj Resurs]. - Rezhim dostupa: URL: //http://www.ereading.club/book.php?book=75189

9.Nikolaeva E.S. Mezhdometiya v pragmalingvisticheskom aspekte (na materiale russkogo i anglijskogo yazykov): dis. ... kand. filol. nauk: 10.02.19 Rostov n/D, 2006. - $180 \mathrm{~s}$.

10. Fatyuhin V.V. Osobennosti perevoda zvukopodrazhanij i mezhdometnyh glagolov (na materiale russkogo i anglijskogo yazykov): dis. ... kand. filol. nauk: 10.02.20 Moskva, 2000. 184s.

11. Lewis C.S. The Chronicles of Narnia. - Harper Collins Children's Books, 2011. - $224 \mathrm{~s}$. 